\title{
COMO OS PROFESSORES DE BIOLOGIA CONCEBEM A DIVERSIDADE CULTURAL: INFLUÊNCIAS PARA O DIÁLOGO INTERCULTURAL E PROPOSTA PARA A FORMAÇÃo DOCENTE
}

\author{
Maria das Graças de Santana Bispo ${ }^{1}$, Geilsa Costa Santos Baptista ${ }^{2}$ \\ ${ }^{1}$ Discente Universidade Estadual de Feira de Santana (UEFS); Grupo de Investigação em Etnobiologia e Ensino de Ciências (GIEEC) \\ ${ }^{2}$ Docente da Universidade Estadual de Feira de Santana e no Programa de Pós-Graduação em Ensino, Filosofia e História das Ciências da Universidade \\ Federal da Babia (UFBA) e UEFS; Grupo de Investigação em Etnobiologia e Ensino de Ciências (GIEEC).
}

Recebido em 08 de outubro de 2018. Aceito em 17 de setembro de 2019. Publicado em 26 de setembro de 2019.

\begin{abstract}
REsumo - Este artigo apresenta e discute os resultados de uma pesquisa qualitativa que teve por objetivo identificar quais são as concepções que os professores de biologia possuem acerca da diversidade cultural presente nas escolas onde atuam e como essas concepções podem influenciar no diálogo intercultural. Realizamos entrevista semiestruturada com 5 professores de biologia e as análises aconteceram de maneira indutiva e em diálogo com a literatura da área de ensino de ciências, a partir de transcrição e categorização. Nossos resultados apontam que os professores concebem como importante a consideração da diversidade cultural, embora existam dificuldades que remetem às suas formações inicial e/ou continuada. Sugerimos abordagens que contribuam para a formação docente culturalmente sensível, o que inclui dimensões da história e da filosofia da ciência bem como da etnobiologia.
\end{abstract}

Palavras-chave: Formação de professores de biologia; Diversidade cultural; Diálogo intercultural.

\section{COMO LOS PROFESORES DE BIOLOGÍA CONCIBEN LA DIVERSIDAD CULTURAL: INFLUENCIAS PARA EL DIÁLOGO INTERCULTURAL Y PROPUESTA PARA LA FORMACIÓN DOCENTE}

Resumen - Este artículo expone y discute los resultados de una investigación cualitativa que tuvo como objetivo identificar cuáles las concepciones que los profesores de biología poseen acerca de la diversidad cultural presente en las escuelas donde actúan y cómo esas concepciones pueden influir en el diálogo intercultural. Se realizaron encuestas semiestructuradas con 5 profesores de biología y los análisis se realizaron de manera inductiva y en diálogo con la literatura del área de enseñanza de ciencias, a partir de transcripción y categorización. Nuestros resultados apuntan que los profesores conciben como importante la consideración de la diversidad cultural, aunque existen dificultades que remiten a sus formaciones inicial y/o continuada. Sugerimos enfoques que contribuyan a la formación docente culturalmente sensible, lo que incluye dimensiones de la historia y filosofía de la ciencia, así como de la etnobiología.

Palabras Clave: Formación de profesores de biología; Diversidad cultural; Diálogo intercultural.

HOW TEACHERS OF BIOLOGY CONCEIVE CULTURAL DIVERSITY: INFLUENCES FOR THE INTERCULTURAL DIALOGUE AND PROPOSAL FOR TEACHER TRAINING

ABstraCt - This study presents and discusses the results of a qualitative research that aimed to identify the conceptions that biology teachers have about the cultural diversity within schools where they work and how these conceptions can influence intercultural dialogue. We conducted a semi-structured interview with five biology teachers and the analysis took place inductively and in dialogue with the literature of the science teaching field, based on transcription and categorization. Our results show that teachers reflect on the importance of considering cultural diversity, although there are difficulties that refer 
to their initial and/or continuing education. We suggest approaches that contribute to the culturally fragile teacher training, which includes dimensions of the history and philosophy of science as well as the ethnobiological dimension.

KEYwORDs: Training of biology teachers; Cultural diversity; Intercultural dialogue.

\section{INTRODUÇÃO}

Desde a década de 1990, a formação de professores tem sido cada vez mais tomada como objeto de estudo por vários pesquisadores (Nóvoa 1992; Ludke 2001; Selles 2002; Silva e Chaves 2009; Gomes 2011). De maneira geral, esses estudos enfatizam a necessidade de superação da racionalidade técnica, que concebe o professor como mero repetidor de conteúdos escolares e o aluno como repetidor desses conteúdos, e a importância de o professor tornar-se um profissional reflexivo e investigador da sua própria prática pedagógica, pois isto poderá contribuir significativamente para melhorias nos processos que abarcam o ensino e a aprendizagem escolar.

De acordo com Schön (1992), a investigação da prática pedagógica, consiste na observação, da identificação de problemas, da análise, da avaliação e de reconstrução da sua ação didática. Concordando com Nóvoa, (2001), a investigação conduz o professor ao seu desenvolvimento profissional, pois lhe permite a reflexão sobre a sua própria ação docente e, consequentemente, a compreensão e tomada de decisões. A investigação guia a ação do professor, dar-lhe elementos para mudar a rotina dentro das salas de aula e adaptá-las às estratégias em função dos grupos e situações particulares (Ramírez 1995).

No que tange aos processos que envolvem o ensino e a aprendizagem das ciências, a ênfase é a mesma, isto é, na necessidade da formação de professores amparada na investigação e na reflexão. A investigação não apenas da própria prática pedagógica, mas, também, dos saberes culturais dos estudantes, como possibilidade de aplicar um ensino que respeita e considera a diversidade cultural, através do estabelecimento de diálogos entre esses saberes e os científicos que são conteúdos de ensino nas salas de aula (Baptista 2014).

Sendo assim, pensar a formação de professores para lidar com a diversidade cultural é também pensar nas realidades escolares, que, em sua maioria, apresentam um público diverso, oriundo de diferentes ambientes socioculturais e, consequentemente, com diferentes formas de pensar e agir perante o mundo em que transita. Para Saviani (2008), é preciso que a educação escolar não desconsidere a bagagem conceitual histórica e cultural dos estudantes, isto é, as suas impressões e vivências acerca do mundo a sua volta, porque os estudantes, quando chegam à escola e salas de aula, não deixam para trás as suas realidades, mas, contrariamente, carregam consigo todo um conjunto de conhecimentos e vivências culturais que muito podem contribuir para a aprendizagem.

Os professores, sejam de ciências ou de quaisquer outras áreas, precisam estar atentos para escutar e considerar as vivências e saberes culturais dos estudantes de maneira investigativa, como estratégia para dar sentido aos conteúdos ensinados, pois, concordando com Baptista (2014, p. 29), a "diversidade de culturas presente nas salas de aula pode favorecer a compreensão dos conteúdos científicos, seja estabelecendo relações de semelhanças e/ ou de diferenças entre esses conteúdos e os conhecimentos culturais dos estudantes".

O estabelecimento de relações entre modos de conhecer pode facilitar a aprendizagem, melhorando a compreensão do conhecimento científico por parte dos estudantes, para que se tornem cidadãos atuantes nas sociedades, sejam elas cientificamente influenciadas ou não. Assim, diante de situações sociais diversas, eles saberão lidar com os desafios de forma crítica, realizando interpretações e tomando decisões que julguem necessárias e/ou adequadas. Isso certamente tornará o ensino de ciências significativo para a vida dos sujeitos e, consequentemente, maior gosto em aprender.

Cabe destacar que a prática pedagógica investigativa para mediação entre saberes pode acontecer através de diálogos, quando os professores motivarão as representações, ajudando os estudantes a compreender os contextos de origem e de aplicabilidade de cada um dos conhecimentos envolvidos, tanto dos conteúdos científicos ensinados, 
quanto dos saberes que são inerentes aos seus meios socioculturais. No ensino de ciências, dialogar consiste na negociação de significados culturais, que partem das relações de comunicação que são estabelecidas entre o professor e os estudantes, e entre os estudantes, sobre um determinado tema que é foco do ensino e aprendizagem, sem que ocorram hierarquizações de saberes (Baptista 2014).

Todavia, uma prática pedagógica investigativa só será possível mediante conscientização da sua importância pelos professores, sendo preciso, portanto, proporcionar a esses profissionais (formação continuada) e aos futuros profissionais (formação inicial), oportunidades para reflexões que partam de questões que podem surgir nas salas de aula (Baptista 2014). De acordo com Gil-Pérez e Vilches (2005) a formação do professor de ciências precisa envolver reflexões epistemológicas. Isto porque as concepções dos professores sobre a natureza da ciência, e como ela se relaciona com outros modos de conhecer, podem influenciar significativamente na forma como eles decidem questões nas salas de aula, incluindo aí a consideração ou não dos saberes culturais dos estudantes e realização de diálogos. Isto envolve identificação e análise das concepções desses profissionais acerca da natureza da ciência, do ensino, da aprendizagem e das interações entre os sujeitos e seus saberes: professores e estudantes e estudantes e os seus espaços socioculturais.

Nesse sentido é que o presente trabalho apresenta e discute os resultados de uma pesquisa de iniciação científica da primeira autora - como bolsista da Universidade Estadual de Feira de Santana (UEFS-BA) - a qual teve por objetivo identificar quais as concepções que os professores de biologia possuem acerca de questões que envolvem a diversidade cultural presente nas salas de aula das escolas da região de Feira de Santana (BA) e como essas concepções podem influenciar no diálogo intercultural, entre os saberes científicos e os saberes dos meios socioculturais dos estudantes. Nosso propósito com isto é contribuir com dados empíricos para as pesquisas voltadas à formação dos professores de ciências e diversidade cultural, especialmente para que estabeleçam o diálogo intercultural no ensino de biologia.

Além de contribuir com dados empíricos, esperamos que os dados apresentados neste trabalho também possam colaborar para elucidação das necessidades, dificuldades e expectativas dos professores de biologia com relação às suas formações para lidar com a diversidade cultural e, por conseguinte, para novos estudos voltados para a formação do professor de ciências e diversidade cultural. De igual forma, contribuir para que melhorias ocorram na formação do professor de ciências, no que tange ao seu papel como investigador da sua própria prática pedagógica e dos saberes culturais dos estudantes. Isto no sentido de que seja um mediador diante das situações diversas as quais ele tem que lidar nas salas de aula, tendo em vista a diversidade cultural nela existente. Por diversidade cultural, entendemos a "variedade de culturas existentes, podendo estar presente em diferentes espaços sociais, sendo representada pelos indivíduos que dela fazem parte" (Baptista 2014, p. 29).

Tendo em mente os aspectos acima mencionados, pontuamos para o nosso estudo o seguinte questionamento: - Quais são as concep̧̧̃oes que os professores de biologia possuem acerca da diversidade cultural e quais são as implicações dessas concep̧̧̃es no ensino que considera e respeita a diversidade de saberes para o diálogo intercultural nas salas de aula?

\section{Abordagem metodológica}

A abordagem aplicada para realização da nossa pesquisa foi qualitativa, buscando amparo nos referenciais teóricos e metodológicos da pesquisa em educação (Ferreira 2015; Martins 2004), em educação em ciências (Matthews 1995; Canen 2001; Cobern e Loving 2001; Mortimer e Scott 2002; El-Hani e Mortimer 2007) e em etnobiologia (Posey 1997; Marques 2001; Campos 2002; Martins 2004). 
Segundo Martins (2004), a pesquisa qualitativa exige particular consideração de questões éticas, dada a aproximação entre pesquisador e pesquisados. No presente estudo, foram consideradas questões éticas, tendo por base as normas propostas na resolução 466/2012, do Conselho Nacional de Saúde (CNS) do Brasil, sobre pesquisa envolvendo seres humanos (Brasil 2012). Assim, para sua realização, conforme solicitado pelo CEPUEFS, obtivemos assinaturas de um Termo de Consentimento Livre e Esclarecido (TCLE) dos sujeitos envolvidos no estudo. Nesses termos apresentamos todas as orientações acerca da pesquisa, bem como os riscos e possíveis desconfortos. Esclarecemos que a qualquer momento da pesquisa, poderiam desistir da participação sem nenhum custo financeiro. Também garantimos manter em sigilo a identidade de todos que concordassem em assinar.

Cumpre informar que a pesquisa ora relatada constitui parte do projeto de pesquisa da segunda autora, orientadora da primeira em iniciação científica junto ao Departamento de Educação da UEFS. O título da sua pesquisa é "A etnobiologia, a história e a filosofia das ciências na formação de professores de ciências para a diversidade cultural: estudo comparativo entre Brasil e Portugal', o qual tem aprovação no Comitê de Ética em Pesquisa Envolvendo Seres Humanos (CEP-UEFS), com parecer número 1.007.254, em 26/03/2015.

\section{Coleta de dados}

A coleta de dados aconteceu entre os meses de agosto e dezembro de 2017 e os meses de abril e junho de 2018, e foi realizada em três etapas interligadas. Na primeira, ocorreu levantamento de dados bibliográficos e documentais que permitiram aprofundamento teórico acerca da temática e amparo à discussão realizada no que tange à formação do professor e o ensino de biologia voltado para a diversidade cultural. O levantamento se deu a partir da identificação de palavras-chave na literatura em educação e educação em ciências nas bibliotecas das universidades Federal da Bahia e Estadual de Feira de Santana e na internet, especialmente no Portal de Periódicos da CAPES, no seguinte endereço eletrônico: http://www.periodicos.capes.gov.br/. As palavras-chave foram: formação do professor de ciências; interculturalidade; diversidade cultural; diálogo intercultural; natureza da ciência; epistemologia de ciências e biologia; ensino de ciências multicultural.

A segunda etapa consistiu na identificação das escolas que queriam participar da pesquisa. Para isto, realizamos visitas às escolas públicas do estado da Bahia da região de Feira de Santana, que atendam estudantes agricultores e/ ou filhos de agricultores. Justificamos a prioridade por estas escolas devido ao fato de o estudo que deu origem à nossa pesquisa ter envolvido esses estudantes e, além disto, por entender que eles são provenientes de comunidades localmente situadas, as quais mantém seus saberes culturalmente ligados à natureza, podendo contribuir ricamente para a facilitação da aprendizagem dos conhecimentos científicos. Nessas escolas, fizemos análises dos Projetos Políticos Pedagógicos (PPP) com o intuito de caracterização das realidades escolares e dos sujeitos participantes. Além disto, também objetivamos verificar abordagens, ou não, de temáticas voltadas para a diversidade cultural. Partimos das mesmas palavras-chave utilizadas no levantamento bibliográfico (Ver parágrafo anterior).

$\mathrm{Na}$ terceira etapa aconteceu a identificação dos sujeitos participantes, que foram os professores de biologia, e das suas concepções com relação à temática formação docente e ensino para a diversidade cultural. Os professores que desejaram participar da pesquisa, após assinarem o TCLE, negociaram dias e horários para realização das entrevistas. As entrevistas partiram do seguinte protocolo de questões, o qual foi elaborado previamente, em parceria com a orientadora. 1- Qual a tua formação na graduação? 2- Possui alguma pós-graduação? 3- Quais componentes curriculares você ensina? 4- Para você o que é ciência? 5- O que é cultura? 6- Você considera importante a consideração dos saberes culturais dos estudantes nos momentos de ensino? Justifique tua resposta; 7- O que significa etnobiologia? 8- Você acredita que os professores de biologia estão preparados para lidar com a diversidade cultural da escola; 9- O que significa diálogo intercultural? 10 - Você planeja suas aulas para a 
consideração da diversidade cultural? 11- Qual a sua sugestão que você daria para uma formação docente em biologia que esteja preparada para lidar com a diversidade cultural presente nas escolas? 12- O que você entende sobre História e Filosofia da Ciência?

É importante informar que duas escolas já haviam sido identificadas para a realização do presente estudo a pedido do CEP-UEFS, a Escola Manuel José Gomes e o Colégio Estadual Áureo Filho, ambas situadas na cidade de Ipecaetá, Bahia. Entretanto, dada as dificuldades de transporte para ter acesso às referidas cidades e a primeira autora residir em Coração de Maria (BA) e a segunda em Feira de Santana (BA), houve remanejamento para estes municípios. Em Feira de Santana, envolvemos o colégio Modelo Luís Eduardo Magalhães. Já em Coração de Maria, participaram os colégios Dom Pedro II, Rômulo Galvão e o Maria José de Lima Silveira. Todos os colégios envolvidos são de natureza pública do estado da Bahia.

\section{Caraterização dos sujeitos e das escolas participantes}

Foram contatados nove professores, porém, após a leitura do TCLE, apenas cinco aceitaram participar. Foram dois professores de biologia do município de Feira de Santana e três do município de Coração de Maria. Os participantes são dos gêneros masculino e feminino, com idades que variam entre 30 e 60 anos. Com relação às suas formações, todos os professores entrevistados possuem graduação em Licenciatura em Ciências Biológicas; dois possuem especialização um em saúde coletiva com ênfase no Programa Saúde da Família (PSF), e o outro em educação sexual e didática, três possuem mestrado na área de educação e biotecnologia. Apesar de todos serem graduados em Ciências Biológicas, uma professora ministra aulas de química e um professor ministra aulas de química e física nas respectivas escolas onde atuam.

No que diz respeito à caracterização das realidades escolares, destacamos que todas as escolas envolvidas estão localizadas em áreas urbanas e atendem estudantes tanto do meio urbano quanto rural dos municípios. $\mathrm{O}$ Colégio Modelo Luís Eduardo Magalhães, está localizado no centro da cidade de Feira de Santana, na Rua Vasco Filho no 15, CEP 44003-246. Possui uma média de 1500 alunos matriculados, funcionando com o Ensino Médio, nos turnos matutino e vespertino. O Colégio Maria José de Lima Silveira está localizado no centro do distrito de Retiro- Coração de Maria, cujo endereço é a Rua Cleto Alves da Cruz, CEP 44250000. Nele estão matriculados estudantes do Ensino Fundamental e Médio (matutino e vespertino), atendendo também a Educação de Jovens e Adultos (EJA) no turno noturno. O Colégio Rômulo Galvão, localizado no centro do município de Coração de Maria, na Avenida João Amorim, n¹70, atende estudantes do Ensino Fundamental, Médio, EJA e cursos técnicos em Análise clínica, Logística, Segurança do trabalho e outros. O Colégio Dom Pedro II, localizado no município de Coração de Maria, situa-se na mesma Avenida do Colégio Rômulo Galvão, atendendo estudantes do Ensino Médio.

Ao analisar o Projeto Político Pedagógico (PPP) das escolas participantes, encontramos perspectivas explícitas de uma educação que considera a diversidade cultural dos estudantes em apenas uma delas: o Colégio Estadual Dom Pedro II. No seu PPP a temática diversidade cultural está na página 19, no item que corresponde aos princípios educativos, o qual aponta que a escola busca planejar suas ações, considerando os diversos saberes culturais dos estudantes. Segundo Silva e Rebolo (2017), indicativos desta natureza permite o aprendizado dos diferentes sujeitos, grupos, sociedades, respeitando e valorizando a diversidade cultural. Segundo a coordenação pedagógica do Colégio Dom Pedro II, a escola ainda não contempla de forma efetiva projetos que abordem a temática da diversidade. No entanto, afirma que deseja pensar e executar projetos que comtemplem o tema de forma significativa, tendo em vista que a escola atende estudantes de diversos meios sociais, especialmente oriundos do campo e de atividades agrícolas da região. Nos PPP das demais escolas não encontramos menção explícita com o termo diversidade cultural, entretanto, identificamos menções sobre a importância de respeitar as 
diferenças presentes nos espaços escolares, bem como apresentar questionamentos que provoquem a curiosidade e apresentação dos conhecimentos prévios pelos estudantes.

Ressaltamos que ao solicitar a leitura dos planos às escolas Rômulo Galvão e Maria José de Lima Silveira, ambas afirmaram estar fazendo atualizações em seus projetos, o que para nós pode significar uma percepção da importância da inclusão da consideração da diversidade cultural presente nessas escolas. Como é possível notar, existem menções do termo diversidade nos PPP, mas não está claro se essa diversidade está atrelada aos meios socioculturais dos estudantes e da biologia, enquanto atividade cultural dos biólogos. Esses documentos apontam que existe uma diversidade nos espaços das escolas, sendo importante considera-las, todavia, sentimos falta de esclarecimentos sobre os significados atribuídos à diversidade bem como de planos de ações que buscassem dialogar com essa diversidade nos momentos de ensino, como indica Fleuri (2003). Isto é preocupante, pois se a escola não prevê em sua política pedagógica a consideração da diversidade cultural atrelando-a aos saberes dos estudantes, os professores podem achar irrelevante abordagens sobre este assunto nas suas aulas, não estabelecendo diálogos entre os conhecimentos científicos escolares e outros modos de conhecer (Silva e Rebolo 2017). Acreditamos que as diferenças culturais devem coexistir nas escolas e salas de aula, fazendo parte das relações interpessoais e das práticas pedagógicas.

\section{Análise de dados}

As entrevistas foram registradas com auxílio de um gravador e transcritas. Para cada entrevistado, foram criados códigos com o objetivo de garantir a sua privacidade, a saber: P1, para o professor entrevistado 1, P2 para o professor entrevistado 2, e assim sucessivamente.

A partir das transcrições das entrevistas, elaboramos categorias temáticas, sempre seguindo os significados interpretados sobre as respostas dadas pelos professores participantes. Dentro de cada categoria, as respostas foram organizadas e analisadas de maneira indutiva e com base na literatura da área de educação e ensino de biologia.

\section{Resultados e Discussão}

As análises das respostas das entrevistas permitiram a geração de seis categorias temáticas. A seguir, cada uma dessas categorias será apresentada e discutida. Importa dizer que organizamos as categorias de acordo com as respostas das perguntas que consideramos mais relevantes para a nossa questão de pesquisa.

\section{Categoria 1: Formação docente para lidar com a diversidade cultural e suas origens}

Ao tratarmos de diversidade cultural, se faz necessário compreendermos o conceito de cultura. As análises sobre as respostas dos professores no Quadro 1 indicam unanimidade no significado do termo cultura, pois, mesmo utilizando palavras distintas, todos eles afirmaram que cultura é a arte e o conhecimento historicamente situado de um povo, características que marcam a vida das pessoas de maneira atemporal. Esse conceito não está errado, segundo o referencial teórico utilizado neste trabalho, pois, concordando com a visão de Geertz (1989), cultura é um sistema de símbolos e significados que permite as interações e a existência humana nos grupos sociais. Os símbolos, para Geertz, são objetos, ações ou acontecimentos que tem significados. A partir disto, percebendo que todos os professores apresentaram um conceito para o termo cultura, seguimos para o Quadro 2, onde 
apresentamos as suas respostas acerca de como acreditam que as suas formações contribuem ou não para lidar com a diversidade presente nos espaços escolares.

Quadro 1. Respostas dos professores participantes para a pergunta: O que é cultura?

P1 - Cultura é informação, cultura é conhecimento, cultura é você poder conhecer novas línguas, novos lugares, é você buscar aprender, se qualificar.

P2 - Cultura é, (eu tive uma vez, em uma pós que en fiz, que o professor disse o seguinte): que a cultura é o conjunto de conbecimentos de um povo. Mas tudo que determinada comunidade produz, é cultura.

P3 - Cultura é a arte de um povo, a bistória de um povo. Aquilo que constitui os ensinos de um povo e que é transmitido de geração em geração.

P4 - É manifestação social, de grupos, de locais.

P5 - Cultura, pra mim, é o conhecimento de cada região, de cada localidade, por exemplo, a gente associa cultura com a questão de um conhecimento específico né? E eu não vejo dessa forma, pra mim a cultura é o conbecimento que cada região tem de tradições próprias daquele local.

Quadro 2. Respostas dos professores participantes para a pergunta: Você acredita que os professores de biologia estão preparados para lidar com a diversidade cultural da escola?

P1 - Ainda não. Por mais que a gente aprenda, que a gente busque fazer pós graduações, que a gente faça cursos. Mas cada ano, não sei...cada turma a gente se depara né, com novidades[...]

$\mathbf{P} 2$ - Não. Eu acho que a gente não está preparado pra isso não. Porque, eu acho que a gente está vivendo um momento que isso está aflorando, de forma bem rápida, então a gente não está preparado, eu acho que não. [...] cursos de formação constantemente, mas verdadeiros, pra gente começar a lidar com essas questões novas que vão surgindo né...

P3 - Deveria estar. E deveria não quer dizer que é ou que não, mas deveria estar. Porque a Biologia precisa discutir diversidade cultural, até porque diversidade cultural é a oportunidade de conhecimento...

P4 - Depende. Tem alguns que sim, e outros não. Pelo menos eu tento, é trazer um pouco, mas eu acho que ainda falta muita coisa a ser colocado, pra chegar esse ponto aí, de diversidade cultural com Biologia.

P5 - Eu espero que sim. [...] eu acho que a gente vai tentando se adaptar, ai eu falo, ai meu Deus como era antes, e agora está, mais ai vamos tentar estudar, pra melhorar, pra verificar, aluno que agora está aparecendo com algumas informações, vamos alertar, vamos conversar.

Quando os professores entrevistados foram questionados se eles se sentem preparados para lidar com as diversas culturas presentes nas escolas onde atuam, eles afirmaram que não, porque não tiveram oportunidades de discutir sobre o assunto em suas formações, e até mesmo pela velocidade e dinamicidade em que as mudanças vêm acontecendo no campo da educação formal. Salientamos que é preciso maior dedicação à formação do professor neste sentido, seja ela inicial e/ou continuada, pois, como bem indica Feitosa e Leite (2012), para atender as atuais exigências educacionais diante das sociedades cada vez mais diversas do ponto de vista cultural é necessário que os professores estejam formados para isto.

A formação de professores que estimule o abandono da pedagogia comumente nomeada de tradicional, que está preocupada unicamente com a transmissão e memorização de conteúdos, sem atribuição de significados culturais pelos estudantes. Essa pedagogia contrapõe a pedagogia sociointeracionista, a qual defendemos neste trabalho, por não considerar que as interações entre os sujeitos nos contextos socioculturais exercem forte influência nos seus desenvolvimentos. Concordamos com o argumento de Vygotsky, de que o desenvolvimento humano acontece do plano social para o individual, das interações socioculturais para as transformações do ser biológico.

No Quadro 2, é possível observar a importância do sociointeracionismo na formação dos professores, por exemplo as falas de P1 e P2, quando indicam a necessidade de cursos que possibilitem aprimorar suas práticas pedagógicas neste sentido. P2 sugere a efetivação de cursos de formação continuada, o qual poderá contribuir para interações dinâmicas entre sujeitos da educação escolar e preparação de professores para lidar com diversidade cultural. Neste sentido, Canen e Xavier (2011) argumentam que a formação continuada facilita interações e promove reflexões acerca da diversidade cultural, tornando-a mais difundida no cotidiano escolar.

$\mathrm{Na}$ fala do P3, percebemos que ele tem uma concepção imparcial, pois apesar de reconhecer que os professores deveriam estar preparados para lidar com a diversidade cultural, ele não aponta o porquê disto e nem as perspectivas 
para mudanças neste sentido. Já P4, embora aponte que existem professores preparados e outros não, ele informa que "tenta", mas não especifica como, reconhecendo que há um longo caminho a percorrer. Destacamos um ponto importante na fala de P4, que é a desvinculação da biologia com o conceito de diversidade cultural, pois, para ele, é difícil discutir diversidade cultural com a biologia. Essa concepção de P4 está equivocada, pois a diversidade cultural também envolve as ciências, não estando restrita às culturas dos estudantes (Aikenhead e Jegede 1999).

A diversidade cultural é inerente tanto à vida dos estudantes quanto às ciências, como atividades culturais dos cientistas. Para Baptista (2014), diversidade cultural é a variedade de culturas existentes, podendo estar presente em variados espaços sociais, sendo representada pelos indivíduos que dela fazem parte. Nas escolas, a diversidade cultural se faz presente por meio dos recursos e materiais didáticos, dos estudantes, dos professores, dos diretores, coordenadores, enfim, toda comunidade escolar. Todavia, a educação escolar que considera importante o respeito pelas culturas, necessita que os professores sejam sensíveis aos diferentes sistemas de saberes, no sentido de estar atentos, investigá-los, compreendê-los e relacioná-los. Porque assim como os cientistas, os estudantes apresentam capacidades cognitivas diferentes, que partem de realidades diferentes e com concepções de mundo diferentes (Mioranza e Roesch 2010).

Categoria 2: Concepção dos professores entrevistados a respeito do que é etnobiologia

No Quadro 3, apresentamos as respostas dos professores acerca do que é etnobiologia para eles. Partindo do pressuposto que os estudos etnobiológicos trazem contribuições relevantes para um ensino que considere os saberes dos estudantes - pois a mesma é caracterizada como uma área do conhecimento que se dedica a estudar o papel da natureza no sistema de crenças e de adaptação humana a determinados ambientes (Posey 1997) entendemos como relevante que os professores de biologia tenham conhecimento a respeito desta ciência e as inúmeras possibilidades de ensino que podem ser desenvolvidas a partir das suas perspectivas.

\section{Quadro 3. Respostas dos professores participantes para a pergunta: O que significa etnobiologia?}

$\mathbf{P 1}$ - Etnobiologia pra mim, é a origem. É o conbecimento do que é nativo, as informacões da própria cultura de um povo das informacôes que eles carregam que eles já têm, já vivem na sua história. Se é uma vila, se um conhecimento que eles têm, se é uma vila de pescadores. Algum lugar que já tem, assim, os conhecimentos já prévios daquela localidade, que você pode transformar, ou melhorar as informaçôes as informações que eles já trazem.

P2 - Essa palavra é a primeira vez que eu escuto. É a primeira vez que eu ouço essa palavra no caso. Eu acho muito importante, eu acho interessante essa proposta, porque, como eu falei antes. Por que você vai pegar a cultura dele, o meio dele, que as vežes você não conhece, ele vai trazer pra gente né?! E a gente pode adaptar, relacionar com o que a gente vai ver em sala de aula, porque eu acho que fica mais fácil pra ele assimilar o conteúdo.

P3 - É a oportunidade de discutir a ciência a partir de uma realidade vivenciada por um povo. A partir dos seus costumes, seja ali, a relação dele com as questões vegetais, com as questões animais, a partir da sua realidade, do senso comum, trazer isso para o meio científico. Então a etnobiologia é a oportunidade de dialogar com a ciência a partir da realidade que o individuo está inserido.

P4 - Etnobiologia pra mim, é uma parte da Biologia que trata de agregar os conhecimentos entre a cultura, folclore, comportamento social de um grupo né, em relação aos seres vivos e aos ecossistemas

P5 - Etnobiologia pra mim é o estudo, né, acredito está meio nessa parte cultural, de você fazer um estudo, por exemplo, das questões, dos valores culturais que eles trazem. A gente pode pensar na etnobiologia, por exemplo, de uma maneira mais ampla, como eu tinha um professor de etnobiolgia que direto fazia pesquisas com comunidades de indios, e ai participava dos rituais, participava de tudo, eu acho que talvez a gente esteja fazendo um trabalho de etnobiologia, na medida em que a gente está mergulhando, na cultura deles.

Ao analisarmos as respostas dos professores no Quadro 3, acerca do significado da etnobiologia, percebemos uma dualidade na conceituação e até mesmo falta de conhecimento a respeito da existência do termo. A resposta de P1, não ficou muito bem esclarecida, no entanto é perceptível que ela atribui o termo aos conhecimentos 
tradicionais; P2 afirma desconhecer o termo etnobiologia, tornando sua resposta fora do contexto da pergunta; P3 afirma que etnobiologia é a oportunidade de discutir ciência com base nas realidades vivenciadas por um povo, e afirma que é uma forma de diálogo entre o conhecimento científico e o tradicional, ou seja, mesmo considerando os conhecimentos tradicionais, o mesmo, segundo ele, precisa ser validado pelo conhecimento científico. Esta visão está equivocada. De acordo com Tréz (2011), o ensino em uma perspectiva etnobiológica não precisa comprometer a identidade cultural nem as epistemologias dos estudantes. Isto é, não é preciso validar o conhecimento tradicional à luz do conhecimento científico. Cada um, possui seus próprios contextos de origem e de validade; P4, não demostrou muita clareza na resposta, afirmando ser uma forma de atribuir os conhecimentos a cultura e a manifestações culturais com a biologia, no entanto não ficou esclarecido que conhecimento estava se referindo; P5, conceitua o termo fazendo correlação com os conhecimentos dos estudantes, ao afirmar que a etnobiologia é o estudo das culturas apresentadas pelos estudantes. E faz menção a importância de mergulhar na cultura, ou comunidade que está sendo estudada. As respostas dadas pelos professores estavam pouco relacionadas ao conceito trazido por Possey (1997), no entanto percebemos que sempre atribuíam o conhecimento tradicional ao científico e as culturas locais, mas não atrelavam a natureza, ao papel da natureza presente nessa área de estudo da biologia.

Categoria 3: Consideração dos saberes culturais dos estudantes como sendo importante para o diálogo intercultural

Apesar do termo cultura ser polissêmico, entendemos que o mesmo possa ser definido com clareza para a perspectiva intercultural. Conforme apresentado na Categoria 1, concordamos que cultura é um sistema de símbolos e significados atribuídos pelos homens (Geertz 1989). Assim, ao tratarmos de uma educação escolar em ciências que leva em consideração os saberes dos estudantes, precisamos ter em mente que esses sujeitos, ao chegar nas salas de aula, não deve ter seus conhecimentos desconsiderados e/ou tidos como errôneos diante dos conhecimentos científicos, porque eles constituem parte dos meios socioculturais onde vivem e lhes são úteis para as suas existências, portanto, possuem significados que são inseparáveis das suas vidas (Baptista 2014). No Quadro 4 apresentamos as respostas dos professores a respeito do que compreendem por diálogo intercultural.

Quadro 4. Respostas dos professores participantes para a pergunta: O que significa diálogo intercultural?

P1 - Acho que diálogo intercultural, é o diálogo que a gente pode fazer, pra buscar conbecimento das diversas formas né! Não só biológicas, mas histórica, relacionando com a geografia, com matemática, várias informações. Intercultural pra mim é isso, várias culturas, várias informaçôes, para que dai a gente possa estabelecer uma forma uma maneira de passar conbecimentos.

P2 - Essa palavra é a primeira vez. que eu escuto. É a primeira vez. que eu ouço essa palavra no caso. Eu acho muito importante, eu acho interessante essa proposta, porque, como eu falei antes. Por que você vai pegar a cultura dele, o meio dele, que as vezes você não conhece, ele vai trazer pra gente né?! E a gente pode adaptar, relacionar com o que a gente vai ver em sala de aula, porque eu acho que fica mais fácil pra ele assimilar o conteúdo.

P3 - É a possibilidade de dialogar com diversas culturas, a partir de uma realidade, por exemplo, a gente não pode perder a oportunidade de dialogar com as questões indígenas, a questão do negro, a questão da regionalização. [...] Então o diálogo intercultural, é eu permitir dialogar, a partir de uma cultura. Não somente, sobre um ponto de vista, mas, sobre diversos pontos de vista que constitui diversos povos, em torno de um único ponto de cultura.

P4 - Diálogo intercultural pra mim...eu não entendo muito dessas coisas de cultura não, mas tudo bem viu. Então, pra mim, intercultural, são as relações existentes entre culturas diferentes.

P5 - [...] Manter esse diálogo no sentido de você compreender aquilo que o aluno traz de cultura, né, você poder trabalhar com isso, que é um projeto que a gente tem na escola, pra fazer esse ano, que é trabalhar sobre, a comunidade [...] De trabalhar desde a espiritualidade que tem aqui, da espiritualidade no sentido amplo, de valores, de tudo, não de uma doutrina especifica né, trabalhar danças, movimentos artísticos, da parte de agricultura, a parte de comercio que tem, todo, todo uma parte. 
Analisando a resposta de P1 e de P3, observamos que elas são semelhantes, pois ambos consideram o diálogo intercultural como relações entre várias culturas, como uma forma de interagir com diferentes formas de pensar, contribuindo, assim, para a aprendizagem do aluno. P2 inicialmente afirma desconhecer o termo e diz ser a primeira vez que escuta falar sobre "diálogo intercultural". Contudo, ressalta que é uma proposta importante, pois é uma forma de estabelecer diálogo entre o conhecimento científico e a cultura do aluno. P4 afirma não ter conhecimento do assunto, no entanto reafirma que intercultura é a relação entre diferentes culturas. Na fala de P5, percebemos que ela compreende o diálogo intercultural como sendo a consideração da cultura do aluno nos momentos de ensino, e faz menção a um projeto da escola que visa fazer um levantamento das manifestações culturais da localidade em que escola está inserida, tornando possível um conhecimento mais a fundo do contexto que esses alunos estão inseridos, buscando diálogo entre os objetivos de ensino da escola com a cultura local.

Para todos os professores entrevistados, é importante considerar os saberes culturais dos estudantes nos momentos de ensino, como pode ser constatado no Quadro 5. As análises das respostas do Quadro 4 e do Quadro 5 indicam que para os professores, ao considerar os saberes dos estudantes, é possível estabelecer um diálogo intercultural, pois esses saberes estabelecem relações com os conhecimentos científicos. Essa concepção está de acordo com os argumentos de Fleuri (2003), para o qual a educação que trabalha a partir de uma perspectiva intercultural foge do ensino transmissivo e estabelece relações entre diferentes sujeitos, promovendo uma educação escolar que agrega significados às suas vidas.

\title{
Quadro 5. Respostas dos professores participantes para a pergunta: Você considera importante a consideração
} dos saberes culturais dos estudantes nos momentos de ensino? Justifique tua resposta.

\begin{abstract}
P1 - Acho sim, acho importante. Porque, aqui na escola por exemplo, nós lidamos com um leque de alunos. Uns que moram da zona rural, uns que moram aqui da cede, uns que vem de escolas particulares, uns que tem todo o conbecimento de escolas públicas. Então eu acho importante a gente ter essa consciência. Que são diferentes, os sabres que eles já vêm aqui pra escola e cotidiano deles e, tentar mostrar a Biologia né, passar para eles as informaçoes que nós temos de uma forma clara, interessante e que eles procurem relacionar com a vida que eles têm. Se é um homem do campo, se não é. Pra se tornar mais fácil e prazeroso esse ensino da biologia.
\end{abstract}

$\mathbf{P} 2$ - É importante. Eu acho importante, porque existe a diversidade, então a gente tem que considerar a diversidade. Mas a gente tem que saber dosar, o conhecimento, essa bagagem que o aluno traz, mas também com os conbecimentos científicos...

P3 - Necessário. Você tem que fazer o levantamento prévio [...] se eu vou trabalhar com meu aluno, botânica, por exemplo, é importante fazer alguns levantamentos. O aluno da zona rural, o que que ele entende de botânica, de planta, de flores, quais ervas tem lá. Antes de entrar, naquele lance de briófitas, pteridófitos, gimnospermas e angiospermas. O aluno já tem um conhecimento prévio, ele sabe que aquela determinada planta, serve pra um chá... Mas, quando você consegue estabelecer essa relação, do que ele tem, com o que de fato é, o conbecimento se torna muito mais significativo.

P4 - Claro. Porque a cultura ela traz em si, comportamentos que levam a pensar de uma determinada forma, a agir, e com isso, interfere no raciocinio e nas conclusões que ele pode tomar acerca de determinados assuntos, como por exemplo, a origem da vida.

P5 - Com certeza, pra gente e pra ele. Porque é o caminho que a gente segue, se a gente não conseguir, por exemplo, aproveitar o que eles tem, e dar por exemplo, digamos assim, uma valorizaça daqueles conhecimentos que eles tem, pra eles se sentirem motivados, se sentirem pertencentes, aquela situação, e entender que aquele conbecimento que ele vai agregar, na escola, é uma coisa importante pra eles, não tem sentido. A gente não pode chegar aqui e esperar que o aluno chegue, $e$ dizer pra ele: tudo que você aprendeu está errado, apaga tudo da tua mente e vamos começar tudo de novo, isso não existe! A ciência já mostrou que a gente parte deles né, do conhecimento que a gente já traz:

\section{Categoria 4. Importância do planejamento das aulas para consideração da diversidade cultural}

No Quadro 6 é possível constatar nas respostas dos professores que eles consideram importante o planejamento de suas aulas para consideração da diversidade cultural. Embora tenha ocorrido variação nos seus posicionamentos. P2 afirma que não considera a diversidade cultural no seu planejamento porque desconhece o perfil das turmas. Entretanto, ressalta que no decorrer das suas aulas, quando surgem oportunidades de tratar do assunto, abre espaços para a consideração. 
Quadro 6. Respostas dos professores participantes para a pergunta: Você planeja suas aulas para a consideração da diversidade?

P1 - Busco. Não sei assim da forma, na maneira que deveria ser, mas eu sempre procuro pensar as minhas aulas, uma
forma diversificada de dar mais informaçôes, de tornar o ensino de Biologia, não uma coisa assim, estática, mas dinâmica,
com novas informaçôes, com novas culturas, para que eles vejam que é muito amplo e admirável né e estudo da Biologia.
P2 - Sinceramente não. Porque eu vejo assim, a questão do conteúdo, eu planejo o conteúdo que eu vou trabalhar! Ai de
acordo com o que vai surgindo na aula, uma dúvida, ou um menino fala da sua experiência, é que a gente vai adaptando.
Porque na escola a gente tem um grupo, a gente nunca sabe o que vai surgir na aula, a como eu trabalho apenas com o
terceiro ano, eu não conheço o aluno, a gente não tem os conhecimentos prévios das turmas, dos alunos que eu vou pegar,
então eu não conheço a realidade deles, então eu não tenho como me preparar pra isso, né.
P3 - Sim, claro. É preciso.
P4 - Sim, na medida do possivel, e na medida do que eu entendo, do que eu leio.
P5 - Sim. Não dá, por exemplo, as vezes a gente vê em outras escolas.... Pra mim, como professora, não dá pra eu pegar
o planejamento do meu colega de lá de feira, de um colégio matutino, de um colégio particular, por exemplo, chegar aqui
e aplicar. A realidade do meu aluno é diferente. Não que você acredite que seja melhor ou pior, não é nada disso, é só
diferente. Então a gente vai tentando adequar a realidade deles [...] adequando a realidade, ao tempo e tudo mais, as
dificuldades são locais mesmo.

Os professores P3 e P4 demonstraram atenção com o planejamento das aulas para consideração da diversidade cultural, porém não explicam como o fazem e se enfrentam dificuldades. Na resposta de P1, ele demonstra considerar a diversidade cultural, buscando adequar os conteúdos ao contexto dos estudantes mediante os momentos de ensino.

P5 também afirma considerar a diversidade cultural no seu planejamento de aula e ressalta que isso é importante, pois cada escola possui um público diferente, com contexto diferente, não sendo possível, portanto, utilizar o mesmo planejamento para públicos escolares diferentes.

Analisando as falas contidas no Quadro 6, e trazendo-as para o contexto das pesquisas voltadas para o ensino de ciências que almeje ser intercultural, ressaltamos a importância de a escola incluir em seu Projeto Político Pedagógico (PPP) ações que motivem o professor a planejar aulas com questões culturais, não apenas nos momentos de ensino, mas, também, em outros momentos, como eventos escolares que envolvem todos os professores, de todas as áreas, constituindo parte da identidade da escola e de todo o corpo docente. Para Candau (2008), a educação intercultural precisa abranger todos os atores e todas as dimensões do processo educativo, e não pode ser reduzida a algumas situações e/ou atividades realizadas em momentos específicos e nem focalizar sua atenção exclusivamente em determinados grupos sociais.

\section{Categoria 5. Compreensão dos entrevistados acerca da História e Filosofia da Ciência e a importância dessa compreensão no ensino}

Ao analisarmos as respostas contidas no Quadro 7, percebemos que todos os professores demostraram insegurança ao serem questionados sobre a história e filosofia da ciência. As suas respostas indicam alguns elementos que indicam isso, como por exemplo na resposta de P5, que revela sua inquietação ao tentar encontrar uma resposta; P1 busca conceituar com base na etimologia das palavras presentes na pergunta e, atribui o conhecimento cientifico às ideias de filósofos; P2 também responde considerando que a história da ciência é marcada pelas descobertas de filósofos e aponta que suas formações eram mais completas e que no, entanto, antigamente, se tinha mais descobertas. Ou seja, segundo ela o conhecimento que temos hoje é consequência dos estudos dos primeiros filósofos. Percebemos em sua resposta a desconsideração dos diversos estudos e descobertas da atualidade, bem como o grande número de pesquisas em andamento; P3 afirma que ciência é investigação e, sendo assim, possui uma história. Ele aponta o senso comum como base para se chegar ao conhecimento científico, permeando pela filosofia, que segundo ele, é quem permite pensar, e com isso se torna possível pensar na história, o que leva a investigação; P4 foi conciso em sua resposta e diz que é o diálogo entre o pensamento e os fatos que já 
aconteceram. Para P4 discutir história e a filosofia da ciência é uma forma de conhecer o contexto, as possibilidades e as condições que o conhecimento é produzido.

Para Santos e Oliose (2012), a integração da história e filosofia da ciência no ensino de ciência ajuda os estudantes na atribuição de significados aos conhecimentos científicos e o estabelecimento de relações entre a ciência e sociedades. Retomando a resposta de P5, percebemos que ela traz uma ressalva interessante a respeito da preparação das suas aulas e a história da ciência. P5 afirma que procura sempre levar para esses momentos um pouco da história da ciência, pois considera que isso é importante para que o aluno tenha acesso ao funcionamento do trabalho científico ao longo dos anos, podendo estabelecer relações com o seu cotidiano.

Penitente e Castro (2010) acrescentam que é importante o professor conhecer e compreender a construção da ciência a partir do seu contexto histórico, pois isto lhe ajudará na compreensão do papel da ciência como um recorte da realidade que se relaciona com outras áreas e atividades humanas.

\section{Quadro 7. Respostas dos professores participantes para a pergunta: $\mathrm{O}$ que você entende sobre História e Filosofia da Ciência (ocidental)?}

\begin{tabular}{|c|}
\hline $\begin{array}{l}\text { P1 - Acho que filosofia é você buscar conbecimento, você buscar alguma informação, é você lidar com essa questão do } \\
\text { homem, do ambiente, da vida né...filosofia é você pensar. E a ciência faz você pensar, a ciência faz você lidar com toda } \\
\text { essa questão do pensamento, das ideias. Se você fala sobre alguma teoria em ciências, você está também falando das } \\
\text { ideias de algum filosofo, de algum pesquisador, de algum cientista, dos pensamentos que eles criaram, pra determinada } \\
\text { situação, pra determinado fenômeno natural, acho que está relacionado ao pensar né, com o trabalhar com a ciência e } \\
\text { com a Biologia. }\end{array}$ \\
\hline $\begin{array}{l}\text { P2 - Sinceramente, se você for parar lá do começo, de Galileu Galilei, é.... a produção cientifica nesse sentido, eu acho } \\
\text { assim que foi bem ampla, lá atrás. Eu acho que antes, essas pessoas tinha uma formação mais completa desses que a } \\
\text { gente tem hoje em dia. Então eles eram filósofos, eles eram biólogos, eles eram geólogos, eles estudavam várias ciências ao } \\
\text { mesmo tempo. Mas de lá até os dias atuais, a gente vê que a ciência ela está bem ampla, em vários campos diferentes né. } \\
\text { E hoje em dia o conhecimento ele é processado de uma forma bem mais rápida. Essa parte aqui eu não estudo muito, } \\
\text { então eu não tenho muita coisa a dizer, não tenho domínio. }\end{array}$ \\
\hline $\begin{array}{l}\text { cia é investigação. Como investigação, ela tem uma história né! Começa do senso comum e o senso comum leva } \\
\text { estigação. E se a história da ciếncia possibilita, a partir do senso comum, até chegar. Com certeza a filosofia, } \\
\text { ù de todas as ciências, ela permeia por á, porque é a arte de pensar. Eu preciso pensar na minha história, } \\
\text { nessa história, buscar a investigação. Ou seja, filosofia, pensar na história, discutir a bistória, e levar a ponto } \\
\text { ação, que é a Ciência, se inter-relaciona. }\end{array}$ \\
\hline $\begin{array}{l}\text { P4 - Eu acho que é o diálogo existente entre o pensamento e os fatos que aconteceram, com a ciência né, o que foi que } \\
\text { naquela época se descobriu dentro da ciência, que contexto histórico era aquele ali, o que se dizia, o que se pensava acerca } \\
\text { daquilo ali, que pode ter influenciado ou não, algumas conclusões dos cientistas. }\end{array}$ \\
\hline 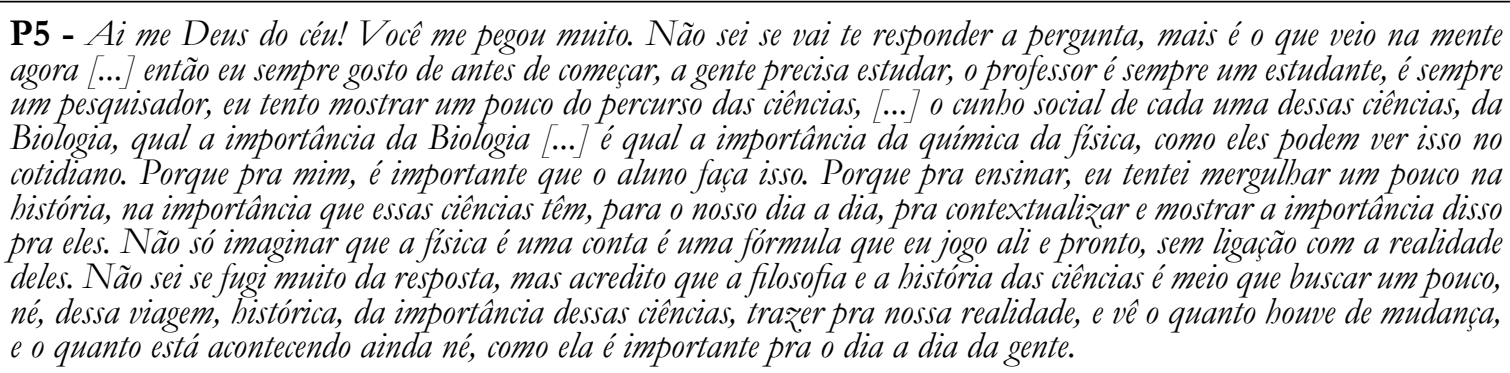 \\
\hline
\end{tabular}

Categoria 6. Sugestões e perspectivas para uma formação docente que lida com a diversidade cultural na escola

No Quadro 8 apresentamos as respostas dos professores acerca de quais sugestões eles teriam para uma formação docente que vise a consideração da diversidade cultural presente nas escolas e salas de aula, tendo em vista que nas suas respostas eles sempre relatavam sobre suas formações, demostrando, por vezes, que suas práticas de ensino poderiam ser melhoradas, caso tivessem a oportunidade de discutir, ou até mesmo trabalhar com assuntos ligados à temática. 
Quadro 8. Respostas dos professores participantes para a pergunta: Qual a sua sugestão você daria para uma formação docente em biologia que esteja preparada para lidar com a diversidade cultural presente nas escolas?

P1 - Eu me senti na forma de conteúdo, preparada. [...] Porque assim, os estágios são bons são, mas eu acho que épouco para que o aluno (graduando) se sinta seguro para poder se formar e já ir pra sala de aula. Eu acho que deveria ter uma preparação maior nesse sentido, ou um estágio mais longo. Começar não nos últimos semestres, mais um pouco antes, para que os alunos (graduando), possam vivenciar mais a sala de aula, porque conteúdo a faculdade da, o aluno estuda né, o graduando estuda. Mas eu acho que essa vivência no dia a dia dessas escolas...eu acho que os estágios deveriam ser um pouco antes realmente.

P2 - Eu acho assim, pessoas que trabalham com isso, no caso, daria pra gente ideias de como trabalhar com isso, entendeu. Projetos pra gente aplicar também na nossa prática. Sair da teoria e ir pra prática, porque tem muita teoria as vezes na universidade e a prática totalmente diferente. Porque a gente vê muitos professores que nunca pisaram na sala de aula do ensino médio, no ensino fundamental, e que tem teorias que na prática não funciona. Você tem uma sala 40, 40 e tantos alunos, e que você não tem como dar assistência a ele com 50 minutos, duas aulas por semana de 50 minutos, $e$ você dá essa assistência, ter essa visão tão ampla, mas ao mesmo tempo individual [...]

P3 - É preciso, que o ensino docente de biologia, esteja mais no campo prático. Somente a academia não forma. É preciso estar no campo prático, eu acho que não só nas disciplinas de estágio supervisionado, mas eu acho que precisa trabalhar mais com a realidade, inclusive do próprio acadêmico, bem como a comunidade onde ele está.

P4 - Eu acho que é preciso, que na academia o estudante, ele leve o rosto da sua comunidade. De repente um trabalho a partir de onde ele fez o ensino médio. Trazer essa realidade para poder discutir a cultura. Porque o tempo que estuda na faculdade, é um tempo de aprendizagem, claro! Mas também é um tempo de construir possibilidades. E se a gente não construir possibilidades, e se a gente não construir a possibilidade de discutir cultura, a partir da realidade que esse aluno, acadêmico, está inserido, como é que ele vai traspor depois de formado? Ele fica as vezes um pouco distante. Então, precisa criar esse feedback, universidade com a realidade que o acadêmico está inserido.

P5 - Primero a melhora na ideia da didática dessa atividade. [...] Porque você tem uma leitura, em determinados momentos, de muitos teóricos, mas teoria e prática, são duas coisas completamente diferentes. E isso, só quando você está na sala de aula, que você percebe isso. [... Então se a universidade tem essa área voltada pra licenciatura, então ela deveria ser feita de forma mais efetiva. Principalmente na parte de estágio. Uma semana de estágio ou uma observação é completamente insuficiente pra botar um aluno, com um pouco mais de segurança na sala de aula. Então melhorar muito essa prática.

Ao analisarmos as falas de P1 e P5, percebemos atenção das suas partes para a importância dos momentos de estágio. Segundo esses professores, os estágios supervisionados durante a licenciatura nas universidades são importantes para a formação docente, contudo, não são suficientes. P1 e P5 argumentam que nas suas experiências na graduação sentiram falta de uma abordagem ou aprofundamento sobre culturas, para que se sentissem mais seguros ao assumir uma sala de aula.

P2 ressalta em sua fala a importância dos cursos de formação para além dos que ocorrem dentro das universidades, bem como a necessidade de projetos ligados à temática, a fim de contribuir para as práticas pedagógicas; P3 acrescenta a importância de formar professores que tenham a possibilidade de relacionar a sua trajetória acadêmica com o seu contexto social de ensino para que o estudante, ao sair da escola e retornar para a sua comunidade, consiga transpor os conhecimentos que aprendeu de forma significativa para a sua realidade local. Além disto, P3 também aponta que o tempo vivenciado pelos licenciandos nas universidades deveria ser um tempo de gerar possibilidades de conhecer diferentes realidades culturais, no aproximar a realidade acadêmica com realidades das escolas e dos seus sujeitos.

Dada as respostas dos professores, inferimos, concordando com Teixeira e Oliveira (2005), que abordagens acerca das relações entre culturas na formação dos professores é fundamental, tanto para o aprofundamento dos estudos acerca das abordagens que considerem a diversidade cultural como para auxiliar os professores que possuem dificuldades em lidar com essas questões.

\section{Considerações Finais}

De um modo geral, nossas análises indicam que os professores de biologia que participaram da nossa pesquisa concebem a consideração da diversidade de saberes culturais como um caminho promissor para facilitação dos 
processos que envolvem tanto o ensino quanto a aprendizagem, embora a tenham como de difícil realização, especialmente por conta de lacunas nas suas formações (inicial e/ou continuada). Esses professores apontaram dificuldades sobre quais caminhos podem percorrer para que consigam investigar e compreender as realidades socioculturais dos estudantes e dos contextos onde as comunidades escolares se inserem. Essas dificuldades inviabilizam o diálogo intercultural durante as aulas, entre os conteúdos da biologia ensinados e os saberes dos meios socioculturais dos estudantes, porque não conseguirão dominar as epistemologias dos conhecimentos envolvidos, podendo planejar aulas que facilitem as participações e representações de saberes.

Os professores apontam como necessária a formação inicial e continuada com abordagens voltadas para diversidade cultural e ensino de biologia, que vá além dos estágios supervisionados, relacionando teoria e prática, aproximando o mundo acadêmico ao mundo escolar. Neste sentido, sugerimos abordagens que contribuam para a formação docente culturalmente sensível, o que inclui dimensões da história e da filosofia da ciência bem como da etnobiológia. As duas primeiras contribuem para que os professores compreendam, entre outros aspectos, a complexidade inerente ao trabalho científico em diferentes épocas bem como a natureza do conhecimento científico (Matthews 1995) e como esse conhecimento se diferencia e se articula com outros conhecimentos, oriundos de outros sistemas de saberes. Já a terceira dimensão, que inclui a etnobiologia, contribuirá para que os professores compreendam que além da ciência ocidental, existem outros modos de conhecer, outros conhecimentos que são culturais e que vem permitindo a diferentes sociedades as suas existências. Além disto, que é possível o estabelecimento de relações de semelhanças e de diferenças entre esses conhecimentos e os conhecimentos que integram os conteúdos de ensino de biologia nas escolas durante o diálogo cultural que seja estabelecido com os estudantes (Baptista 2012). A etnobiologia é uma ciência que busca compreender os conhecimentos e as conceituações desenvolvidas por qualquer sociedade e suas culturas a respeito da biologia (Posey 1997). Dito em outras palavras, a etnobiologia é o estudo das relações entre os seres humanos e os demais seres vivos tendo as culturas como mediadoras desse processo.

Se abordagens da história, da filosofia e da etnobiologia estiverem presentes na formação dos professores de biologia, as novas gerações desses profissionais terão novas oportunidades de tornarem-se críticos e comprometidos com o ensino efetivo e de qualidade para saber lidar com as realidades dos estudantes, tornando possível o diálogo intercultural. Por conseguinte, a construção do conhecimento científico biológico dentro dos seus contextos de origem e de aplicabilidade.

\section{REFERÊNCIAS}

Aikenhead G, Jegede O.1999. Cross-cultural science education: A cognitive explanation of a cultural phenomenon. Journal of Research in Science Teaching, 36(2), p. 269-287.

Baptista GCS. 2015. Um enfoque etnobiológico na formação do professor de ciências sensível à diversidade cultural: estudo de caso. Ciência \& Educação, Bauru, 21(3), p. 585-603.

Baptista GCS. 2014. Do cientificismo ao diálogo intercultural na formação de professores e ensino de ciências, Interações, 311, p. 28-53.

Brasil. 2012. Ministério da Saúde. Conselho Nacional de Saúde. Comissão Nacional de Ética em Pesquisa. Normas para pesquisa envolvendo seres humanos. Brasilia.

Campos MD. 2002. Etnociências ou etnografia de saberes, técnicas e práticas. In: AMOROSO, M. C. de M. et al. Métodos de coleta e análise de dados em etnobiologia, etnoecologia e disciplinas correlatas. São Paulo: UNESP/CNPQ, p. 46-92. 
Canen A. 2001. Universos culturais e representações docentes: subsídios para a formação de professores para a diversidade cultural. Educação \& Sociedade, 77, p. 207-227.

Canen A, Xavier GPM. 2011. Formação continuada de professores para a diversidade cultural: ênfases, silêncios e perspectivas.

Revista Brasileira de Educação, Belo Horizonte, 16 (48), p. 641-813.

Candau V. M. 2008.Direitos humanos, educação interculturalidade: as tensões entre igualdade e diferença. Revista Brasileira de Educação, Rio de Janeiro, 13(37), p. 45- 185.

Cobern WW, Loving CC. 2001. Defining science in a multicultural world: Implications for science education. Science Education, 85, p. 50-67.

El-Hani CN, Mortimer EF. 2007. Multicultural education, pragmatism, and the goals of science teaching. Culture Studies of Science Education, 2, p. 657-702.

Feitosa RA, Leite RCM. 2012. A formação de professores de ciências baseada em uma associação de ofício. Revista ensaio, Belo Horizonte, 14(1), p. 35-50.

Ferreira CAL. 2015. Pesquisa quantitativa e qualitativa: perspectivas para o campo da educação. Revista mosaico, Brasília, 8(2), p. 173-182.

Fleuri RM. 2003. Intercultura e educação. Revista Brasileira de Educação, 23, p. 16-35.

Gil-Pérez D, Vilches. 2005. Inmersión en la cultura científica para la toma de decisiones ¿necesidad o mito? Revista Eureka sobre Enseñanza y Divulgación de las Ciencias, 2(3), p. 302-329.

Gomes RCM. 2011. A formação dos professores no contexto atual. Revista de Educação, 14(18), p. 103-125.

Lüdke M. 2001. A complexa relação entre o professor e a pesquisa. In: André, M. (Org.). O papel da pesquisa na formação e na prática dos professores. Campinas: Papirus, p. 27-54.

Marques JGW. 2001. Pescando Pescadores. $2^{\mathrm{a}}$ Ed., São Paulo: NUPAUBUSP.

Martins HTS. 2004. Metodologia qualitativa de pesquisa. Educação e Pesquisa, 30(2), 300 p.

Matthews MR. 1995. História, filosofia e ensino de ciências: a tendência atual de reaproximação. In: Cadernos Catarinense de Ensino de Física, 12(13), p. 164-214.

Mioranza AJ, Roesch IC. 2010. A diversidade cultural no cotidiano da sala de aula. In: Simpósio Nacional de Educação, 2. Cascavel. 1, p. 1-13.

Mortimer EF, Scott PH. 2002. Atividades discursivas nas salas de aula de ciências: uma ferramenta sóciocultural para analisar e planejar o ensino. Investigações em Ensino de Ciências, 3(3), p. 283-306.

Nóvoa A. (Org.). 1992. Os professores e sua formação. Lisboa: Dom Quixote.

Nóvoa A. 2001. Professor se forma na escola. Revista Nova Escola, São Paulo, 142, p. 13-15.

Penitente LAA, Castro RM. 2010. A História e Filosofia da ciência: contribuições para o ensino de ciências e para formação de professores. Pesquiseduca, São Paulo, 2(4), p. 232-244. 
Posey DA. 1997. Etnobiologia: teoria e prática. In: Ribeiro D (ed.). Suma Etnológica Brasileira, 115. Edição atualizada do Handbook of South American Indians. 3a Edição, v. 1, Petrópolis: Vozes/FINEP.

Ramírez T. 1995.El rol docente-investigador en Venezuela ¿Mito o realidad? Venezuela: Ed. Núcleo de investigaciones filosóficas del IPC, 62 p.

Saviani D. 2008. História da história da educação no Brasil: um balanço prévio e necessário. Eccos Revista Científica, 10(Esp).

Schön DA. 1992. Formar professores como profissionais reflexivos. In: NÓVOA, António. Os professores e sua formação. Lisboa - Portugal: Dom Quixote.

Selles SE. 2002. Formação Continuada e desenvolvimento profissional de professores de ciências: anotações de um projeto. Ensaio: Pesquisa em Educação em Ciências, 2(2), p. 1-15.

Silva PSA, Chaves SN. 2009. Epistemologia, ética e política na formação de professores de ciências. In: Ensaio: Pesquisa em Educação em Ciências, 11(2), p. 230-244.

Silva VA, Rebolo F. 2017. A educação intercultural e os desafios para a escola e para o professor. Interações (campo Grande), 18(1), p. 180-190. http://dx.doi.org/10.20435/1984-042x-2017-v.18-n.1(14).

Teixeira LCRS, Oliveira AM. 2005. A relação teoria-prática na formação do educador e seu significado para a prática pedagógica do professor de biologia. Ens. Pesqui. Educ. Ciênc. (Belo Horizonte), Belo Horizonte, v. 7, n. 3, p. $220-242$.

Tréz TA. 2011. Feyerabend, interculturalismo e etnobiologia: algumas possíveis articulações no ensino de Biologia. Biotemas, 3(24), p. 129-140.

Vilela-Ribeiro EB, Benite AMC. 2009.Concepções sobre natureza da ciência e ensino de ciências: um estudo das interações discursivas em um Núcleo de Pesquisa em Ensino de Ciências. Revista Brasileira de Pesquisa em Educação em Ciências, 9(1), p. 1-21. 